\title{
O QUE PODEMOS FAZER PARA EVITAR A DESTRUIÇÃO DO NOSSO MUNDO?
}

\author{
Por José Luiz de Andrade Franco*
}

DIAMOND, Jared. Colapso: como as sociedades escolhem o fracasso ou o sucesso. Rio de Janeiro: Record, 2005. 685p. ISBN 8501065943. [Traduzido do original Collapse: how societies choose to fail or survive. London: Penguin, 2005. 576 p. ISBN 0-14027951-2]

A história ambiental, disciplina surgida nos anos 1970, é praticada sobretudo nos países de língua inglesa. Ela tem se dedicado a compreender como os seres humanos foram, através dos tempos, afetados pelo seu ambiente natural e, inversamente, como e com que resultados eles afetaram esse ambiente. De modo geral, ela ainda esbarra nas resistências - internalizadas há muito pelas ciências humanas -, do paradigma durkheimiano de que o social se explica apenas pelo social. Esta percepção era bastante justificada na época do próprio Émile Durkheim, quando as disciplinas que se dedicavam aos estudos do homem e da sociedade estavam delimitando os seus campos e sofriam com as tentativas de transposição mecanicista de conceitos das ciências naturais, como no caso das teorias do darwinismo social, de Spencer, ou do determinismo geográfico, de Ratzel.

Hoje, no entanto, estamos confrontados com o fato de que a sobrevivência da espécie humana mantém íntima dependência de um ambiente natural, uma vez que este mostra-se suscetível à nossa

* Doutor em História pela Universidade de Brasília (UnB) e pesquisador colaborador do Centro de Desenvolvimento Sustentável (CDS/UnB). 
capacidade de explorá-lo e transformá-lo, por vezes radicalmente. Em face disso, o apego ao paradigma durkheimiano é um anacronismo capaz de embotar a capacidade de os cientistas humanos e sociais estudarem a questão ambiental e entreverem as soluções mais apropriadas para os dilemas ambientais contemporâneos.

Para os historiadores ambientais, trata-se, justamente, de entender como e em que medida ambiente e sociedade se influenciaram mutuamente, ao longo de períodos geralmente longos de tempo. Este tipo de preocupação é exatamente o que encontramos no livro Collapse: how societies choose to fail or to survive (Colapso: como as sociedades escolhem o fracasso ou o sucesso), de Jared Diamond, traduzido para o português e publicado no Brasil pela editora Record, em 2005, mesmo ano de seu lançamento nos Estados Unidos.

Diamond, norte-americano, iniciou a sua carreira científica com um doutorado em Fisiologia, especialidade que abandonou para desenvolver pesquisas no campo da Ornitologia, tornando-se um profundo estudioso da ecologia das aves das florestas tropicais da Nova Guiné. Nos anos 1970, desenvolveu estudos relacionados com a aplicação da teoria do equilíbrio da biogeografia de ilhas, formulada por Edward O. Wilson e Robert MacArthur, tornandose um dos fundadores e principais expoentes da recém-surgida disciplina de Biologia da Conservação. Atualmente é professor do Departamento de Geografia da Universidade da Califórnia, em Los Angeles.

Prestigiado, tanto no ambiente acadêmico, como entre os ambientalistas, Diamond tem se dedicado nos últimos anos a escrever livros de escopo mais amplo e com apelo editorial para o público geral. Ele se consolidou nessa linha de publicações com Guns, germs and steel: the fates of human societies (Armas, germes e aço: os destinos das sociedades humanas) - publicado no Brasil, também pela editora Record, em 2002), com o qual faturou, em 1998, o 
Prêmio Pulitzer. Esse livro procurou responder à seguinte pergunta: por que, nos últimos 13 mil anos, a experiência humana no planeta se mostrou tão variada, no espaço e no tempo? Tratava-se, portanto, de compreender a diversidade cultural, econômica, tecnológica e mesmo civilizatória das populações humanas. A resposta, audaciosa e intrigante, é que os diferentes grupos humanos, embora dotados de uma capacidade equivalente de construir civilizações, foram fortemente condicionados por fatores naturais (climáticos, biológicos, geológicos etc.). Ou seja, Diamond inseriu-se na melhor tradição dos historiadores ambientais, ao incluir fatores não-humanos e não-sociais nas suas explicações de fenômenos sociais e culturais. Munido de um relativismo cultural típico dos antropólogos, ele critica e refuta explicações baseadas em determinismos biológicos, genéticos ou raciais. No entanto, como profundo conhecedor dos processos do mundo natural, ele não tem medo de apontar os fatos naturais que explicam certos fatos sociais.

Em Colapso, Diamond continua nessa linha e se dedica a responder outra pergunta: o que podemos fazer para evitar a destruição do nosso mundo? A estratégia escolhida foi a comparação entre sociedades do presente e do passado, que tenham entrado em colapso ambiental ou enfrentado essa ameaça. Segundo o autor, "o livro emprega o método comparativo para compreender colapsos sociais que tiveram a contribuição de problemas ambientais". Ele cunha o conceito de ecocídio, que significa o suicídio ecológico não-intencional, para explicar situações em que grupos sociais acabam por destruir inadvertidamente os recursos ambientais de que dependem para a sua sobrevivência.

Diamond entende que os colapsos tendem a seguir cursos similares, fazendo variações sobre um mesmo tema, como em um arranjo de jazz. Desse modo, ele estabelece oito processos por meio dos quais sociedades do passado danificaram o ambiente em que viviam: 1) desmatamento, 2) destruição do habitat, 3) problemas com 
o solo (erosão, salinização e perda de fertilidade), 4) problemas com o controle da água, 5) sobrecaça, 6) sobrepesca, 7) efeitos de espécies exóticas introduzidas sobre as espécies nativas, 8) aumento per capita do impacto do crescimento demográfico. As sociedades contemporâneas adicionaram a esta lista mais quatro problemas de alcance global: 1) mudanças climáticas provocadas ou aceleradas pelo homem, 2) acúmulo de produtos sintéticos e/ou tóxicos no ambiente, 3) carência de energia, 4) utilização cada vez maior da capacidade fotossintética do planeta.

Para prosseguir na sua comparação entre sociedades do passado e do presente, Diamond trata de dirimir querelas de matiz antropológico. Ele procura enfraquecer a resistência à idéia de que os povos do passado tenham feito algo que contribuísse para o seu próprio declínio. Mostra que, no que diz respeito ao manejo sustentável dos recursos naturais, o Homo sapiens, desde que desenvolveu a inventividade, a eficiência e as habilidades de caçador, há uns 50 mil anos, tem enfrentado desafios e dificuldades criadas pela sua própria capacidade de superar esses desafios. As posições extremadas dos racistas, de um lado, e dos defensores de um Éden povoado por "bons selvagens", por outro, acabam por cometer o erro de encarar os povos antigos como fundamentalmente diferentes (inferiores ou superiores) dos povos modernos.

Após alertar para o fato de que os colapsos sociais não podem ser atribuídos integralmente a danos ambientais, Diamond constrói uma estrutura analítica de cinco possíveis fatores que podem resultar em colapso ambiental: 1) dano ambiental, 2) mudança climática, 3) vizinhança hostil, 4) diminuição do apoio de parceiros comerciais amistosos, 5) respostas da sociedade aos seus problemas ambientais. Esta estrutura é utilizada como ferramenta ao longo das quatro partes e dos 15 capítulos nos quais se divide o livro. A Parte 1 é composta apenas pelo primeiro capítulo sobre os problemas ambientais contemporâneos do sudoeste de Montana, nos Estados 
Unidos da América (EUA). Montana não se encontra à beira de um colapso ambiental, mas o estudo da sua situação proporciona a vantagem analítica de ocorrer em uma sociedade moderna que enfrenta problemas ambientais típicos e bastante familiares - rejeitos tóxicos oriundos da mineração, manejo de florestas, uso intensivo dos solos e da água, mudanças climáticas, perdas de biodiversidade e introdução de espécies exóticas invasoras. O quadro de Montana facilita comparações com o que aconteceu em sociedades do passado remoto. Diamond demonstra as perdas econômicas ligadas a esse passivo ambiental e conclui que se e como os problemas serão resolvidos irá depender das atitudes e valores adotados pelos habitantes de Montana.

A Parte 2 se distribui por nove capítulos, que tratam de sociedades do passado que fracassaram ou obtiveram sucesso em manejar os seus recursos naturais diante de situações de colapso social iminente. Os exemplos de sociedades que entraram em colapso incluem as civilizações da ilha de Páscoa e das ilhas Piticairn e Henderson, no Oceano Pacífico; os anasazis, do atual sudoeste dos EUA; os maias, nos atuais México e América Central, e os vikings, na atual Groenlândia. As sociedades analisadas que obtiveram sucesso em superar catástrofes iminentes foram os inuits, na atual Groenlândia, a sociedade nórdica (os vikings), na atual Islândia, o Japão da era Tokugawa, as populações indígenas das terras altas da atual Nova Guiné e a população da pequena ilha de Tikopia, no Oceano Pacífico. Aqui, também, Diamond aponta as escolhas feitas pelos habitantes dessas diversas regiões como fatores de seu fracasso ou sucesso em gerenciar os seus recursos naturais.

A Parte 3 tem quatro capítulos, que nos trazem de volta ao mundo moderno. As questões tratadas dizem respeito: 1) às conexões ambientais da catástrofe de Ruanda, na África, sobretudo, relacionadas com o crescimento populacional, com mudança climática e com danos ambientais; 2) ao compartilhamento da ilha 
de Hispaniola, no Oceano Atlântico, pelo Haiti - afetado por um colapso ligado à destruição de suas florestas- e pela República Dominicana - em situação econômica e social melhor e com suas florestas ainda viáveis; 3) à China, que, pelo grande tamanho, população numerosa e sua economia, sofre pesadas doses dos doze tipos de problemas ambientais que afetam as sociedades modernas, com consequências que extrapolam as suas fronteiras; 4) à Austrália, que ocupa um ambiente natural bastante frágil e vivencia problemas ambientais graves, sendo obrigada a considerar a necessidade de uma reestruturação radical de sua sociedade.

A última seção do livro, Parte 4, contém três capítulos, com títulos bastante sugestivos - "Por que algumas sociedades tomam decisões desastrosas?", "Grandes empresas e meio ambiente: condições diferentes, resultados diferentes" e "O mundo como um polder: o que isso representa para nós atualmente?”. Eles procuram trazer algumas lições práticas e relevantes. O primeiro tenta responder à pergunta que nos fazemos, perplexos, a respeito de toda sociedade do passado que acabou destruindo a si mesma: como uma sociedade não percebe perigos que, analisados em retrospecto, parecem tão evidentes? Diamond indica uma série de fatores relacionados com atitudes e valores que conduzem a escolhas desastrosas, a começar pela incapacidade de prever problemas, chegando a conflitos de interesse que permitem que determinados membros da sociedade persigam objetivos vantajosos para si próprios, mas desastrosos para os demais. O segundo destes três últimos capítulos analisa o papel das grandes empresas no mundo moderno. Algumas são incluídas entre as forças causadoras dos maiores danos ambientais, enquanto outras são apresentadas como capazes de fornecer exemplos de práticas e soluções para problemas ambientais. Por fim, o último capítulo trata das principais ameaças ambientais enfrentadas pelo mundo em tempos passados, dentro da premissa de que a globalização torna impossível que as sociedades modernas entrem em colapso isoladamente. Segundo Diamond, "pela primeira vez na história, 
enfrentamos o risco de um colapso global. Mas também somos os primeiros a desfrutar da oportunidade de aprender com o que ocorre com sociedades em todas as partes do mundo atual, bem como com o que ocorreu em sociedades do passado".

Vale chamar a atenção para o fato de que o livro não é apenas sobre fracassos. Ele trata, também, de sociedades bem-sucedidas no enfrentamento de situações de colapso iminente. Apesar de lidar com situações de catástrofe e desastre ambiental e social, Diamond é otimista ao acreditar que as escolhas feitas pelos homens podem garantir, para eles próprios e para o planeta, um futuro de sucesso. Sobretudo, ele acredita que as escolhas certas, no que diz respeito ao manejo sustentável dos recursos naturais, ainda podem ser feitas.

Como ensaio de História Ambiental e de Sociologia Ambiental, Colapso propõe uma mudança de paradigma, capaz de tornar os humanos menos autocentrados e mais conscientes de nossas interações com o ambiente natural, do qual fazemos parte e com o qual interagimos cotidiana e profundamente. 